\title{
Knowledge Mobilization in Chinese Education Policy-Making: Conceptual Frameworks for Motivation Analysis of Policymakers' Adoption of Research
}

\author{
Leiyu $\mathrm{Mo}^{1^{*}}$, Chengwen Hong ${ }^{2}$ \\ ${ }^{1}$ School of Management, China University of Mining and Technology, Beijing, China \\ ${ }^{2}$ Institute of Higher Education, Beijing Normal University, Beijing, China \\ Email: *ronmo2008@163.com
}

How to cite this paper: Mo, L. Y., \& Hong, C. W. (2018). Knowledge Mobilization in Chinese Education Policy-Making: Conceptual Frameworks for Motivation Analysis of Policymakers' Adoption of Research. Creative Education, 9, 1027-1041. https://doi.org/10.4236/ce.2018.97076

Received: May 10, 2018

Accepted: June 5, 2018

Published: June 8, 2018

Copyright $\odot 2018$ by authors and Scientific Research Publishing Inc. This work is licensed under the Creative Commons Attribution International License (CC BY 4.0). http://creativecommons.org/licenses/by/4.0/

\begin{abstract}
Increasing investments and efforts were devoted to Chinese educational policy research in past decades, yet the adoption of research reports remains limited. The education policymakers, who take superior roles as knowledge users, are decisive in mobilizing the research results to policy-making. This study, based on knowledge mobilization framework, had clarified the role of Chinese education policymakers as knowledge user and privilege side in research adoption. Their motivations for research adoption are analyzed: Political motivations and knowledge motivations are initiative and core motivations, while environment influences and knowledge mobilization (KMb) efforts are decisive catalysts and facilitators. In Chinese education system, the environment for decision making and relationship between researchers and policymakers are quite diverse, while knowledge mobilization (KMb) efforts are still limited. Suggestions were provided for building healthy networks and effective mobilization.
\end{abstract}

\section{Keywords}

Knowledge Mobilization, Education Policy-Making, Research Adoption, Motivation Analysis, Conceptual Frameworks

\section{Introduction}

There have been calls for education in placing far greater reliance on research evidence as basis for adoption of programs and practices, especially efforts by America and British government, flagship initiatives in What works Clearinghouse (WWC) and Evidence for Policy and Practice Information and 
Co-coordinating Center (EPPI-center) (Rober, 2008). Ongoing fiscal pressures, ever-growing democratic demand of citizens require more evidence-based policy-making. However, it is an oft-cited problem that social science research use remains modest for policymaking, and bitterly contested in the education field since 1980s. Studies showed the loose relationship between researchers and policymakers, particularly continual disappointment and disparity between high expectations for, and the low perceive impact of, the research (Behrstock, Drill \& Miller, 2009; Levin, Cooper, Arjomand \& Thompson, 2010; OECD, 2007). How to mobilize knowledge get from education research to better educational policy-making still remains unclear.

Three crucial questions that help clarifying: 1) How can we measure the efficiency of research products be used or influence policy-making? 2) Who were in the privilege position in mobilizing the research knowledge into policy? 3) Can we analyze and proper use the motivations that may influence the key person or organization in order to mobilize the research products in a more effective and practical way?

This study starts from answering the three questions according to the situation in China, aims to restructure the process under the rationale of knowledge mobilization, and forms a conceptual framework that reflect factors that influence the key person in China's educational policy-making.

\section{Background and Context}

In China, large investment was given to social science research, since social reform called for sound evidence and better use of think tanks. Projects were mainly commissioned by government bureau. The policy research projects do not receive enough consultative reports, let alone the adoption rate of the submitted reports remain low (Table 1 ).

Actually, Chinese policy makers were require but not force to use research evidence, and were in the privileged position in deciding which information source would be take accountable in policy-making process. So make policymakers more receptive to include research evidence into their decision-making is the most crucial part in mobilizing research products into policy in China.

This study, took "knowledge mobilization" (KMb) as the key concept, provided a Chinese version of $\mathrm{KMb}$ in educational policymaking. We explored the motivations that may influence research adoption of Chinese educational policymakers from four perspectives: political motivation, knowledge motivation, environment influences and knowledge mobilization efforts. Conceptual frameworks would make with the reference from emergent patterns of political science and knowledge management, and Chinese local experiences and factors would be complimented.

\section{Definitions and Scope}

Before further analyzed on motivations for policy makers' adoption, we would 
Table 1. Humanities and social sciences research in Chinese universities \& Colleges.

\begin{tabular}{|c|c|c|c|c|c|c|}
\hline \multirow[b]{2}{*}{ Year } & \multirow{2}{*}{$\begin{array}{l}\text { Projects } \\
\text { sponsored by } \\
\text { government }\end{array}$} & \multirow{2}{*}{$\begin{array}{l}\text { Invested } \\
\text { human } \\
\text { resources }\end{array}$} & \multirow[b]{2}{*}{$\begin{array}{c}\text { expenditure } \\
\text { (hundred RMB) }\end{array}$} & \multicolumn{2}{|c|}{ Applied Reports } & \multirow{2}{*}{$\begin{array}{r}\text { Adoption } \\
\text { rate (\%) }\end{array}$} \\
\hline & & & & $\begin{array}{c}\text { Reports } \\
\text { submitted }\end{array}$ & $\begin{array}{c}\text { Report } \\
\text { adopted }\end{array}$ & \\
\hline 2006 & 123,584 & $58,642.5$ & $14,330,115.7$ & 22,659 & 3945 & 17.4 \\
\hline 2007 & 146,050 & 62,237 & $18,031,367$ & 15,286 & 2626 & 17. 2 \\
\hline 2008 & 171,084 & 64,117 & $23,431,185$ & 7570 & 3905 & 51.6 \\
\hline 2009 & 193,383 & $64,342.6$ & $29,315,739.7$ & 5679 & 3347 & 58.9 \\
\hline 2010 & 226,226 & $68,240.5$ & $36,601,929.6$ & 6464 & 3545 & 54.8 \\
\hline 2011 & 260,905 & $73,337.3$ & $47,468,108.2$ & 8166 & 4562 & 55.9 \\
\hline 2012 & 291,606 & $81,206.3$ & $53,699,133.9$ & 8878 & 4407 & 49.6 \\
\hline 2013 & 313,461 & $84,623.6$ & $57,599,680.3$ & 9486 & 5074 & 53.5 \\
\hline 2014 & 345,119 & 88,552 & $729,189,573$ & 10,659 & 5138 & 48.2 \\
\hline
\end{tabular}

Source: Ministry of Education, P. R. China. Source: China Education Statistical Yearbook (Ministry of Education, 2007-2015).

clarifying the concept of knowledge mobilization and the stakeholders within the process.

The term Knowledge Mobilization (KMb) refers to moving available knowledge (often from formal research) into active use. More than just "bridging the gap", KMb seeks to make connections between research/expertise and policy/practice in order to improve outcomes in various organizations or sectors (wikipedia.org).

Knowledge Mobilization (KMb) is characterized and differentiate by three perspectives:

Firstly, $\mathrm{KMb}$ reconstitute the relationship between researchers and policymakers, rather than principals and agents, they were knowledge producers and users. It emphasizes the multidimensional, longer-term, political and social nature of the work in comparison to earlier terms.

Secondly, $\mathrm{KMb}$ contains all the activities, dissemination platform as well as strategies, investments and efforts involving in the interaction, not only endeavor from the two sides, but also the intermediaries' efforts. "Mobilization" implies effort and direction, not just random interaction, but multiple, iterative phases including in the generation of new research when needed, the communication and application of established research knowledge, and the contextualization of research to suit particular environments.

Thirdly, the knowledge here is understood as any of all the accumulated knowledge and experiences from researchers and stakeholders for social sciences and humanities research (SSHRC, 2013). So the contents of knowledge remain open for $\mathrm{KMb}$, not only the sound results from random-sampling but also the speculative papers published by the researchers from the fields.

Understanding of $\mathrm{KM}$ has been growing in the past decade due to increasing 
interest in the topic as a way to improve public services (Cooper et al., 2009; Davies, Nutley, \& Smith, 2000).

In this study, we would confined our investigation only in the KMb in education policy-making in China, which emphasis on the efforts that done by researchers, policymakers and other intermediaries that may help educational policy makers to make better-informed decisions.

As for producer-user model, there are three main elements-the producer (researcher with research products), the user (policy makers who are in decisive positions in policy-making), and the intermediaries (activities, efforts, strategies that invested in) through which these are linked. Environment works as exogenous influences for the other three elements. In some presentations the elements are framed in much more complex ways than in others-for example with more mediating and moderating variables, or with various recursive elements, or with all sorts of feedback loops-but those main elements are present in almost all of the examples we could find. $\mathrm{KMb}$ is not only a matter of producing more knowledge, but also improving both the desire and capacity for its use in the mediating process (Levin, 2006) (Figure 1).

The three elements are working interactively, and environments influence every element as the $\mathrm{KMb}$ process goes. It is often the case that knowledge users may have the rights to choose the products while intermediaries' may work as advertisement or selling platform, and the buying price and quantity are decided by the demands and supply of the sector-seeing who is in advantage.

In Chinese education sector, policy makers usually in an advantage position, they have decisive power in research adoption choosing from massive and unevenly developed research products, however they usually couldn't find suitable evidence for their immediate use. Professional $\mathrm{KMb}$ intermediaries remains unexplored, while most policy researchers are enthusiastic about policy use and struggling out to play the intermediaries' role, but they have difficulty in both understanding the users' needs and access to the decision maker. Since it's

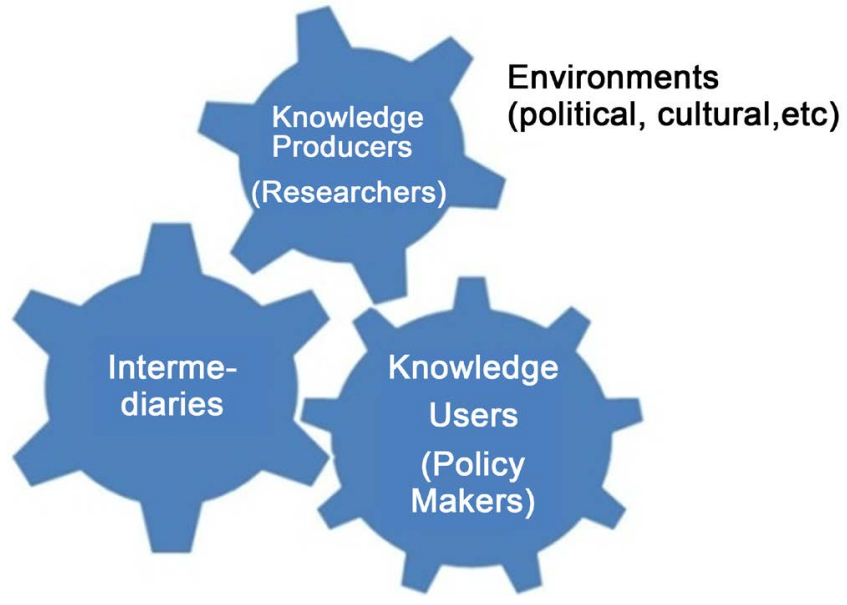

Source: Levin, 2006.

Figure 1. Knowledge Mobilization in policy-making. 
unpractical yet costly to make the policymakers-the knowledge users to choose the right products, it is the producer that should make more efforts. It is important for producers to know the factors that may motivate their users, so they may interactively make more suitable knowledge products, in a more efficient manner, and use at its maximum.

\section{Motivation Components for Knowledge Mobilization of Policymakers in China}

The factor that may influence policy makers to adopt research results to inform or influence in the policy-making could be complex. But in the KMb process, knowledge users could be treated as a group of consumers that care effectiveness and efficiency. As for the user, it is clear that value, supply, expectation of the products, as well as the marketing strategies may influence the demand of the products. For the policy research products, the value, supply, expectations are inherited in its knowledge and political significance. Since there are no accurate standard and requirements, the value, supply, expectations are depending on the judgements of the user (policy-makers), and marketing strategies in the $\mathrm{KMb}$ process could be $\mathrm{KMb}$ efforts, and influenced by the environments.

In this study, we hold the motivations for education policy-makers to adopt research products are divided into three aspects: political motivation, knowledge motivation, environment influences and $\mathrm{KMb}$ efforts that devoted in. The detailed factors may support by existing models or studies across the disciplines. Integrated them, add Chinese characteristics, and cultivated with experts, we concluded the following factors that may well influence the Chinese education $\mathrm{KMb}$ (see Table 2).

\subsection{Factors That Consist the Motivations}

Supported by theories from political and management science, consulted experiences from abroad and at home, lessons from $\mathrm{KMb}$ in healthcare and other field, the following factors may influence the $\mathrm{KMb}$ of education policymakers in research adoption in China, and they would be well included in the motivations we mentioned before.

\subsection{The Motivations \& Their Relations}

The motivations for education policymakers to adopt the research are factors that may inspire or stimulate policymakers to use the idea, results, or suggestions of the research to inform their decision-making. Under $\mathrm{KMb}$ frameworks, it means, the policymakers will have the willingness to "buy" and have controllable cost and channels in using the researches. The willingness of the policymakers would come from their political and knowledge needs and pressure, which are core motives, while environment influences and knowledge mobilization (KMb) efforts are decisive catalysts and facilitators. Among them, political motivations are inherited in bureaucratic instinct of the policymakers, knowledge motivations 
Table 2. Factors that consist the motivations in Chinese education KMb.

\begin{tabular}{|c|c|c|c|}
\hline \multirow[t]{3}{*}{ Political Motivations } & Internal impulses & \multicolumn{2}{|c|}{$\begin{array}{l}\text { Internal dissatisfaction; Systemic collapse; } \\
\text { Incentives for promotion \&power enhancement } \\
\text { Willingness to make a difference }\end{array}$} \\
\hline & External impulses & \multicolumn{2}{|c|}{ Economic change/competition } \\
\hline & Political capacity of policymakers & \multicolumn{2}{|c|}{ Organizing; Decision-making; Critical thinking; Foreseeing } \\
\hline \multirow[t]{4}{*}{$\begin{array}{l}\text { Knowledge } \\
\text { Motivations }\end{array}$} & Value of knowledge & \multicolumn{2}{|c|}{$\begin{array}{l}\text { Scarcity and irreplaceability, Pertinence, actionable; Comprehensiveness, Feasibility, } \\
\text { Timeliness; Presentation, }\end{array}$} \\
\hline & Validity and Reliability & \multicolumn{2}{|c|}{ design, sampling, integration of research process } \\
\hline & Knowledge capacity of policymakers & \multicolumn{2}{|c|}{ Retrieval; Absorb; Preserve; Interpret; Synthesize and Integrate; Problem-Solving; } \\
\hline & Individual knowledge preference & \multicolumn{2}{|c|}{ attitude toward research results; Motivation of using research results } \\
\hline \multirow[t]{6}{*}{$\begin{array}{l}\text { Environment } \\
\text { Influences and } \mathrm{KMb} \\
\text { Efforts }\end{array}$} & $\begin{array}{l}\text { Dissemination strategies and } \\
\text { channels }\end{array}$ & Direct & $\begin{array}{l}\text { Commissioned investigations and projects; } \\
\text { official hearings, service on governmental panels, comments on } \\
\text { policy drafts; suggestion letters to policymakers }\end{array}$ \\
\hline & & Indirect & $\begin{array}{l}\text { News releases; opinion leaders; media interviews; Professional } \\
\text { training for policymakers; Co-supervision of postgraduates, etc. }\end{array}$ \\
\hline & $\mathrm{KMb}$ strategies & $\begin{array}{l}\text { products, events } \\
\text { and networks }\end{array}$ & $\begin{array}{l}\text { Websites, publications, Lectures, conferences seminars, Symposia, } \\
\text { exhibitions. etc. }\end{array}$ \\
\hline & Scholar source & \multicolumn{2}{|c|}{ Type of the Research Institutes; Research reputation; Geographic location } \\
\hline & Previous collaborations & \multicolumn{2}{|c|}{ Frequency of Person-to-person contact; frequency of other contacts } \\
\hline & Policy-making process & \multicolumn{2}{|c|}{ Extent of control; institutionalization of process } \\
\hline
\end{tabular}

signified values that may brought about, environment would provide "budget line" and basic infrastructure, $\mathrm{KMb}$ efforts would broaden the choices.

Political motivation is the initial driving force and directly related to personal career development of policy makers. Adoption of research results may result in problem/crisis-solving, optimization of performance, power enhancement, possibility of promotion and better living for the general public, in case the political capacity of policymakers would control the situation. Knowledge motivations, which would revealed and trigged by the value, validity, reliability of the knowledge provided, influenced by the personal knowledge capacity and preference of policymakers. In Chinese education system, the environment for decision making and relationship between researchers and policymakers are quite complex, and different from other countries and system, which signify the political and culture backgrounds in China. So the following part would analyze the factors that included in Environment Influences and KMb Efforts in detail.

\subsection{Environment Influences and KMb Efforts in China}

Since environment influence and $\mathrm{KMb}$ is the most decisive and characteristic element in $\mathrm{KMb}$ frameworks, and may vary for different country and sector, we would analyze it in detail. 


\subsubsection{KMb Efforts}

Many organizations are increasing their efforts in $\mathrm{KMb}$, including large international bodies such as the World Bank and the OECD. New organizations, such as the Campbell Collaboration, have been created for the purpose of knowledge mobilization. The activities of these organizations range from websites, newsletters, audio-visual products, seminars, conferences, and "learning communities" to organizational infrastructures and policies in support of research and evidence.

$\mathrm{KMb}$ strategies, including products, events and networks are used to show the extent and ability of $\mathrm{KMb}$ efforts. Cooper \& Levin defined the three strategies in 2010, and may localized in China (Table 3).

There are no definite conclusions on which products, events or networks would work more effectively than the other, and the studies supposed that the more activities were taken, the better the KMb works. Based on this assumption, the analysis of websites being conducted by OISE (Ontario Institute for studies in Education) team by University of Toronto admittedly indicates that most organizations are devoting little if any effort to $\mathrm{KMb}$ activities beyond paying "lip-service". It revealed that faculties of education also appear to give little attention to organized $\mathrm{KMb}$, notably so in comparison to technology transfer or industry liaison efforts in areas such as science or medicine which are much better organized and supported. In Kaplan and Haenlein's (2009) model, producer push mechanisms such as RSS feeds or emailed research bulletins to networks may be less effective than online strategies that allow more two-way communication (such as Facebook, Twitter), but the former might reach far more people (due to modest participation with social media tools).

In China, more $\mathrm{KMb}$ events use different networks are emerging, research products are made more user-friendly. Researchers are adapt to more flexible and various way of expressing their research products. Although there is no obvious sign that policy makers become more open to latest research results, they surely exposed to more information that contain research products. But when choosing the "political right" and "reliable" products, the scholar source and

Table 3. Components of KMb efforts.

\begin{tabular}{llll}
\hline Strategy & Definition & Examples & Remarks: \\
\hline $\begin{array}{l}\text { Products } \\
\text { Research reports, adapted products tailored for audiences, } \\
\text { systematic reviews, policy-related documents, terms/glossary, } \\
\text { reference lists \& annotated bibliographies that produced specially policymakers } \\
\text { for users. }\end{array}$ & $\begin{array}{l}\text { e.g. tool kits for } \\
\text { practitioners, briefs for }\end{array}$ & $\begin{array}{l}\text { Personnel resources, activities devote to } \\
\text { the KMb work, and training on packing } \\
\text { the knowledge products and marketing } \\
\text { them. }\end{array}$ \\
$\begin{array}{l}\text { Events } \\
\text { Activities aim to mobilize the research results to policy-related }\end{array}$ & $\begin{array}{l}\text { conferences, professional Video clips of events also included } \\
\text { development training, }\end{array}$ \\
$\begin{array}{l}\text { Networks } \\
\text { Database, apps, platforms that facilitating dissemination of } \\
\text { policy makers }\end{array}$ & $\begin{array}{l}\text { Blog, Facebook, Twitter, WeChat, QQ, weblog in China } \\
\text { listservs, wikis in other } \\
\text { country. }\end{array}$
\end{tabular}

Source: Levin, 2006. 
previous collaborations between the policymaker and the scholars' also matters.

\subsubsection{Scholar Source}

The type of the research institute, as well as its research reputation and geographic location would shape government-research institute engagement, and will effect on the decision of policymakers' selection of scholars and adoption of their research results.

\section{-Type of the Research Institutes}

Different type of research institutes may differ in mission, social and political ties to the policy systems, bureaucratic affiliations, resource allocation within the system, staff time and quality, standards for promotion, etc. In China, it is the organizations' bureaucratic affiliations play the central role, and the conditions mentioned above are more or less related to their affiliations, and could be divided into the following three types according to its extent of dependent relationship to the government.

\section{1) Governmental Research Institutes (GRIs)}

GRIs include functional departments, consulting divisions on educational policy and regulation making in Chinese ministry of education, and also in provincial, city, county level education administration bureau. Their staffs are public servants and resources were sponsored by government. Their mission is directly provide drafts and suggestions to policymakers, present education statistics that collected by the executive branch, and organize hearings and collect public advice for policies. Their research products are directly use by relevant decision-making. But limited to their tight schedule and bureaucratic and task-base thinking style, they are more bureaucrats or officials rather than researchers.

\section{2) Semi-Governmental Research Institutes (semi-GRIs)}

Semi-GRIs include institutes affiliated or attached to the governmental consulting divisions, mainly affiliation of GRIs in national, provincial, city, county levels. For example, The National Education Development Research Center in China, which established upon approval of the state council in 1986 and affiliate to the ministry of education, is built to meet the need of education development and reform, and provides consultation for national macro decision-making. National Institute for Educational Research (NIER), is also renowned as an important national Semi-GRI. Key research projects in national and ministerial-levels or local levels are usually undertaken by them-large-scale investigations and experiments could be done with the help of administrative instruction from government. Their projects are always commissioned by policymakers rather than through rigorous competition. Although there are some celebrated researcher leading the projects, and the newly-enrolls should meet some requirement-their research products are accomplished in a mixed manner under their loose quality supervision system.

3) Non-Governmental Research Institutes (NGRIs)

NGRIs are research institute that are not directly connected to the govern- 
ment, including educational research institutes in universities and colleges, and professional association and private-run research centers. Although most of the universities in China, especially ones with educational research institute were run by government, and professional associations are usually got funds and supports from the government, the relationships between them are looser than that of GRIs and Semi-GRIs.

The NGRIs are unevenly developed, while some of them did systematic and high-quality studies with abundant resources, most of the educational research, like the situation in other countries, are small scale, poorly sponsored. But in its independent position (or at least supposed to be), researchers in NGRIs should offer their knowledge to the powerless, the under-represented and the voiceless rather than to governments and political elites.

Besides, there is a group of research VIPs that worth special attention, since their suggestions and ideas would directly transmit to the policymakers and have profound effects on relevant policies. These elites include experts who work in Counsellors' Office of The State Council of China, academicians in Chinese Academy of Science or Engineering, etc. For example, the question "why we couldn't cultivate exceptional talents in Chinese education system?" ask by Qian Xuesen (a famous academician) had initiated another round of rethinking and reforms in our schools and education system.

\section{-Research reputation;}

Influential research institutes and universities are those have good research reputation, signified reliable source of knowledge, information and advices. Whose voices are most prominent would surely influence the final decision-making (Clarance, 2002).

There are some fairly large and influential specialized educational research organizations such as NIER (National Institute of Education Sciences), and some private-run research centers as $21^{\text {st }}$ Century Education Research Institute. Still large proportion of educational research institutes has been a small scale, fragmented cottage industry hidden away in university faculties or start-up companies.

\section{-Geographic position}

Research show proximity is critical for forming intensive bilateral relations between private firms and universities, probably increased role of trust and face to face contacts when dyadic, confidential and often tacit knowledge exchanges are at stake (Jackson et al., 2007). And the same happen between educational research institutes and educational policymakers, as knowledge producers and users. In order to contact in a face-to-face manner while cost efficient, experts in Beijing were more likely to be invited to ministry of education to give consultations or lectures because of geographic advantage, especially for Beijing Normal University, which is both reliable and in close range.

\subsubsection{Previous Cooperation}

Having contacts and building trust is important for knowledge transfer and ex- 
change as well as to see change in practice (Mitton et al., 2007).

On the one side, professionals as well as policymakers, who had experience conducting research used it more (Belkhodja, 2007). That means the more policymakers exposed to the research activities, the more they would aware and adopt research results. On the other side, strong, long-term linkage between producers and users of knowledge will lead to higher levels of utilization (Nyden \& Wiewell, 1992). Building new relations are considered to be time consuming and could be risky, especially in conservative and accountability-related context. Previous operations not only increase the familiarity between researchers and decision-makers, but also gain some trust.

High-frequencies of the cooperation in a face-to-face form would be benefit for forming a personal connection, which remains to be the most powerful vehicle for moving evidence into decisions in China. High-frequencies in other forms would also beneficial for building mutual trust.

\subsubsection{Policy-Making Process}

Education policies are "living things" forged within national and organizational frameworks (Power, 2007). As an inertly political process, the most decisive institution in education policymaking should be the institutionalization of the policy-making process and the extent of control by policymakers.

-Institutionalization of process

There are three questions that may relate to the research adoption in the institutionalization of process:

The first question is, whether investigation or collecting research results is an obligatory procedure in the policy-making process? UK government's introduction of a cyclical spending review process is based on substantiated submissions to the Treasury from each government department at least offer the rhetoric of a place for research in policymaking and an opening for researchers to press their case (William, 2001), which provide a good model. Nowadays, the Chinese educational policies in national and most provincial level need investigation and discuss phase, but it is not always a necessary procedure in the county or district level.

The second question is, is there a formal standard for choosing the evidence? Many commentators have disparaged policy-makers as impatient and overly concerned with short-term political appeal rather than effectiveness (El-Khawas, 2000). So if there is no formal standard for selection of research they may adopt, the results they may use could be a tool for pull through the priorities and pressures facing by the government or reason for their already-in-mind decisions

The third question is, how would the research be used?

If we are to understand policy-making, and the place of research evidence within it, we have to acknowledge "...the messy realities of influence, pressure, dogma, expediency, conflict, compromise, intransigence, resistance, error, opposition and pragmatism in the policy process" (Ball, 1990: p. 9).

Studies of policy-making do suggest that it is not a linear rational-analytical 
process of examining all the evidence and research results from different context may suggest opposite opinions. Repetitive discussion and interaction between policymakers and researchers would reduce the misinterpretation, and form a better-fit conclusion.

\section{-Extent of control}

The authoritativeness and weights of policymakers in the policy process would definitely influence whether research result could finally transform to a policy. And that would be shown as their extent of control during the policy-making process.

Public policies are developed and delivered through the use of power. In many countries, this power is ultimately the coercive power of the state in the hands of democratically accountable politicians. There sometimes seems then to be a tension between power and knowledge in the shaping of policy. Emphasizing the role of power and authority at the expense of knowledge and expertise in public affairs seems cynical; emphasizing the latter at the expense of the former seems naïve (William, 2001). So it is important to balance the two.

The attitudes of senior managers and political leaders would influence the use of evidence in a less democratic system in the policy-making process. And let the research results to decide the future may lead to elites to manipulate the policy seems to be unfair too.

\section{Considerations for Policy and Discussion}

As the models would reveal, and take the practical situations in China as reference, there are some suggestions that could help increase the adoption of research results in policymaking, and promote $\mathrm{KMb}$ in education policy-making.

\section{1) Establish communication channels and infrastructure}

Education expert fora that bring together researchers and policy-makers, would stimulate the generation, presentation and dissemination of systematic knowledge on education (Teichler, 2000). And the communication channels and infrastructure would be the basis for creation of interpersonal, cross-organizational networks, which valued much in research adoption (Levin \& Fullan, 2008).

Sponsored conferences and research impact networks, as already exist in European countries, could be a model for us. A platform, contain database, that engage with ultimate decision-makers and their policy advisors, identifies new research opportunities, seed-funds promising projects, which could broker, tender, manage and quality-assure research undertake by the network, establish and refine research and policy agendas would be ultimate option (Power, 2007). Inter-institutional mechanisms for fund distribution, shared meeting spaces, institutional commitment, details of people's workload adjustments, communication strategies, and access to data management and storage programs need to be addressed to initiating a collaboration (Curwood et al., 2011).

2) Institutionalize the take-in of research

Firstly, make searching research results or investigation as an indispensable legal 
procedure of policy-making. Introduce mechanisms for ensuring policy-makers are required but also supported to participate in learning communities.

Secondly, standard or indicators must be developed to measure the quality of research results that may adopt as reliable evidence. The validity, reliability, as well as their value should be properly evaluated.

Thirdly, the adoption of knowledge should be completed in an interactive manner and balanced with other considerations. Mutual understanding and comprehensive conclusions would only be reached through interactions. Besides, adopting research results do not mean to ignore the complexities in the situation and judge on cold data that provided, the balance and benefit of stakeholders always matters. Relevant rewards and promotion institutions should be built to inspire researchers to be involved in the procedures.

3) Support researchers in repacking and network maintaining professionally

Present information to policymakers in user-friendly formats would facilitate their decision-making. Provide detail on "what works" and by definitive "facts" about the social world in its actual state would help explain the usage of the research (Davies, 2000). Personnel and writing help would promote the effects.

Professional assistance in translating complex research into straightforward language and pleasant format, relationship-building with user groups through frequent seminars or other interactive activities arrange by specially-assigned person and systematic training would form a long-term and effective KMb system.

4) Help policy-makers to make most value from research evidence

On the one side, the advancement of policymakers' political capabilities as well as their knowledge capabilities would be the most effective way of getting most value from the research evidence. Policy makers work in Canada health sector had been suggested to have core competencies include "proficiency" in evidence-informed decision making, which conclude collaboration, problem framing, critical thinking, innovation and creativity (Pierson et al., 2012). These may take time but worth it.

On the other side, technical, financial, organizational and emotional support for research-based protocol and tools are also suggested (Nutley, Walter, \& Davies, 2007). In some countries, intermediaries, usually third parties are introduced to take the role. In China, existing resources can be integrated and mobilized in a proper way to allocate the resources more reasonably. For example, the scattered, small scale research institutes could form their advantage of integrating research results and transfer into summaries or short videos rather than doing policy research that contain limited value; professional associations may organize activities and in charge of network building among the research institutes and relevant policy making agencies. But of course, promotion standards and targets of the organizations should change accordingly.

5) Prevention of possible damages to academic freedom

For one thing, studies done or sponsored by promoters are much more likely 
to produce positive evidence (Lexchin, Bero, Djulbegovic, \& Clark, 2003). Research engagement in the policy-making process could retrospectively support the policy initiatives have been recognized as policy-based evidence-making in medical and financial fields (Giles, 2010). Educational policy researches in China, although mostly done by NGRIs, were frequently sponsored by the government, would also have political considerations in drawing the conclusions, which may reduce and not eliminate by rigorous sampling and dedicated conduction and rational reasoning.

For the other, the over-emphasis on explicit forms of knowledge in established models, neglecting the importance of socialization and tacit forms of knowledge (Oborn et al., 2013) should be carefully prohibit, in order to balance the research development.

What's more, some criticized on modifications in research agenda could happen to cater for the demand of policy makers (Cohen et al., 1998). But it is the duty and freedom for researchers to balance and select the topics of research, especially in policy research field, which could be seen as an applied subject and aim to make change in existing policies.

\section{Conclusion and Further Studies}

Increasing investments and efforts were devoted in Chinese educational policy researches in past decades, yet the adoption of research reports remains limited. The education policymakers, who take superior roles as knowledge users, are decisive in mobilizing the research results in policy-making. Under the frame of knowledge mobilization, this study formed a composite model for motivations of policy makers' research adoption on the basis of theories from political science and management science, experiences from abroad and at home, and lessons from $\mathrm{KMb}$ in education, healthcare and other field. Political motivations, as well as knowledge motivations, environment influences and $\mathrm{KMb}$ efforts work integrate, influence the adoption behavior of Chinese education policymakers. Suggestions were made on channels and infrastructure building, institutionalization of research take-in process, professional supports on repacking the products and maintain good producer-user networks, and help policymakers to make most value from the products. And there also raised the problem of possible damage to academic freedom that we have to prevent and reduce the disadvantages to certain extent.

The growing awareness of the importance of $\mathrm{KMb}$ is a necessary first step to increase its profile internationally. This awareness is being followed by governmental support and dedicated resources in many places (Cooper, Levin, \& Campbell, 2009). However, it is also revealed that action for KMb is needed on several fronts simultaneously-to improve our understanding of and base of evidence on knowledge mobilization, and to strengthen and evaluate $\mathrm{KMb}$ strategies in a range of organizations. Co-ordination and planning among the organizations are expected. 
To extend the research arena, research is needed to track the practice of education policy-making process, and evaluation tool for KMb in Canadian education system would copiloted by data collected in Chinese situation. And it is hoped that this present paper will encourage others interested in all aspects of $\mathrm{KMb}$ in education to use and develop the models it describes in order to produce more sophisticated ways of analyzing the complex processes involved in this important area.

\section{Fund}

This paper is supported by the Youth Project of National Education Science Planning, Ministry of Education, P.R. China, EFA 140356: Motivation Analysis of Educational Decision Makers' Research Adoption: From the Perspective of Knowledge Management.

\section{References}

Ball, S. J. (1990). Politics and Policy Making in Education. London: Routledge.

Behrstock, E., Drill, K., \& Miller, S. (2009). Is the Supply in Demand? Exploring How, When, and Why Teachers Use Research. Learing Point Association. https://files.eric.ed.gov/fulltext/ED512564.pdf

Belkhodja, O., \& Landry, R. (2007). The Triple-Helix Collaboration: Why Do Researchers Collaborate with Industry and the Government? What Are the Factors That Influence the Perceived Barriers? Scientometrics, 70, 301-332.

https://doi.org/10.1007/s11192-007-0205-6

Clarance, W. (2002). Conflict and Community in Sri Lanka. History Today, 52, 41-47.

Cohen, W. M., Florida, R., Randazzese, L., Walsh, J., \& Noll, R. (1998). Industry and the Academy: Uneasy Partners in the Cause of Technological Advance. Challenges to Research Universities. Washington, DC: Brookings Institution Press.

Cooper, A., Levin, B., \& Campbell, C (2009). The Growing (but Still Limited) Importance of Evidence in Education Policy and Practice. Journal of Educational Change, 10, 159-171. https://doi.org/10.1007/s10833-009-9107-0

Curwood, S., Munger, F., et al. (2011). Building Effective Community-University Partnership: Are Universities Truly Ready? Michigan Journal of Community Service Learning, 10, 15-26.

Davies, H., Nutley, S., \& Smith, P. (2000). What Works: Evidence-Based Policy and Practice in Public Services. Brestol: The Policy Press. https://doi.org/10.2307/j.ctt1t892t3

El-Khawas, E. (2000). Patterns of Communication and Miscommunication between Research and Policy. In: S. Schwarz, \& U. Teichler (Eds.), The Institutional Basis of Higher Education Research (pp. 45-56). Dordrecht: Springer.

Giles, C. (2010). UK QE: Policy-Based Evidence-Making. Financial Times. http://blogs.ft.com/money-supply/2010/02/04/uk-quantitative-easing-policy-based-evi dence-making/

Jackson, R., Baird, W. , Davis-Reynolds, L., Smith, C., Blackburn, S., \& Allsebrook, J. (2007). The Information Requirements and Information-Seeking Behaviours of Health and Social-Care Professionals Providing Care to Children with Health Care Needs: A Pilot Study. Health Information and Libraries Journal, 24, 95-102.

https://doi.org/10.1111/j.1471-1842.2007.00700.x 
Kaplan, A., \& Haenlein, M. (2009). Consumer Use and Business Potential of Virtual Worlds: The Case of "Second Life". International Journal on Media Management, 11, 93-101. https://doi.org/10.1080/14241270903047008

Levin, B. (2006) How Can Research in Education Contribute to Policy? Review of Australian Research in Education, 15, 693-705.

Levin, B., \& Fullan, M. (2008). Learning about System Renewal. Educational Management Administration \& Leadership, 36, 289-303. https://doi.org/10.1177/1741143207087778

Levin, B., Cooper, A., Arjomand, S., \& Thompson, K. (2010). Increasing Research Use in Canadian Secondary Schools. Paper presented at the Canadian Society for the Study of Education Conference, Montreal, Canada. http://www.oise.utoronto.ca/rspe/UserFiles/File/CSSE-CEA_Interventions_Final.doc

Lexchin, J., Bero, L., Djulbegovic, B., \& Clark, O. (2003). Pharmaceutical Industry Sponsorship and Research Outcome and Quality: Systematic Review. British Medical Journal, 326, 1167-1170. https://doi.org/10.1136/bmj.326.7400.1167

Mitton, C., Adair, C., McKenzie, E., Patten, S., \& Perry, B. (2007). Knowledge Transfer and Exchange: Review and Synthesis of the Literature. Milbank Quarterly, 4, 729-768. https://doi.org/10.1111/j.1468-0009.2007.00506.x

Nutley, S., Walter, I., \& Davies, H. (2007). Promoting Evidence-Based Practice: Models and Mechanisms from Cross Sector Review. Research on Social Work Practice, 19, 552-559. https://doi.org/10.1177/1049731509335496

Nyden, P., \& Wiewell, W. (1992). Collaborative Research: Harnessing the Tensions between Researcher and Practitioner. The American Sociologist, 24, 43-55. https://doi.org/10.1007/BF02691930

Oborn, E., Barrett, M., \& Ricco, G. (2013). Knowledge Translation in Healthcare: Incorporating Theories of Learning and Knowledge from the Management Literature. Journal of Health Organization and Management, 4, 412-431. https://doi.org/10.1108/JHOM-01-2012-0004

OECD (2007). Evidence in Education: Linking Research and Policy, Centre for Educational Research and Innovation. Paris: Organization for Economic Co-Operation and Development.

Pierson, L., Ciliska, D., et al. (2012). Building Capacity for Evidence-Informed Decision Making in Public Health: A Case Study or Organizational Change. BMC Public Health, 12, 1-13. https://doi.org/10.1186/1471-2458-12-137

Power, (2007). Organized Uncertainty: Designing a World of Risk Management. Oxford: Oxford University Press.

Rober, E. (2008). What Works? Issues in Synthesizing Educational Program Evaluations. Educational Researcher, 37, 5-14. https://doi.org/10.3102/0013189X08314117

SSHRC (2013). Tri-Agency Open Access Policy on Publications. Social Sciences and Humanities Research Council of Canada. http://www.science.gc.ca/eic/site/063.nsf/eng/h_F6765465.html?OpenDocument

Teichler, U. (2000). Preface. In U. Teichler, \& J. Sadlak (Eds.), Higher Education Research: Its Relationship to Policy and Practice (pp. xi-xiii). Oxford: Pergamon and IAU Press.

William, S. (2001). Evidence Based Policy: Whence It Came and Where It's Going, ESRC UK Centre for Evidence Based Policy and Practice: Working Paper 1. https://www.kcl.ac.uk/sspp/departments/politicaleconomy/research/cep/pubs/papers/a ssets/wp1.pdf 